\title{
Research on Beijing Industrial Energy Efficiency under Industry Updating and Transfer
}

\author{
Jingmin Wang ${ }^{1, ~ a, ~ Y u f a n g ~ S h i ', ~ b ~}$ \\ ${ }^{1}$ North China Electric Power University, Baoding, China \\ ${ }^{2}$ North China Electric Power University, Baoding, China \\ awangjmtc@163.com, bsyf_92@163.com
}

\begin{abstract}
Keywords: Industry upgrading and transfer; Industrial energy efficiency; DEA-Malmquist model; System cluster analysis

Abstract. Industry upgrading and transfer is an important way of the industry collaborative optimization in Beijing-Tianjin-Hebei, and the research on energy efficiency has important practical significance in the process of industrial transfer and upgrading. Based on the capital, labor and energy consumption as input indicators, industrial added value as the expected output indicator, carbon dioxide emissions as the unexpected output indicator, this paper uses the DEA-Malmquist model to measure total factor energy efficiency of Beijing, including 36 sub-industrial sectors and they are divided into high, medium and low energy efficiency industry by using the system cluster analysis. Then we calculate the total factor energy efficiency index and its decomposition index of Beijing industry in 2005-2013. The empirical analysis draws that the overall industrial energy efficiency shows an upward trend. And the technological progress is the main driving factor and the difference of pure technical efficiency is the main reason for the gap among the industries.
\end{abstract}

\section{Introduction}

Government work report promoted strategy of Beijing-Tianjin-Hebei collaboration development for country's top development strategy in 2014. Industrial collaborative development as an important joint is the foundation of Beijing-Tianjin-Hebei collaboration development. Energy efficiency is an unavoidable problem in the process of industrial upgrading and transfer. If we transfer or increase production capacity without considering resource constraints and energy efficiency optimization, it will cause a lot of resource consumption and serious environmental pressure. The industrial sector in Beijing still consumes large energy and the energy economic efficiency is low, which is the focus of industrial upgrading. To study the industrial energy efficiency of Beijing can provide the basis for the formulation of policies and strategies for the coordinated development of industry in Beijing.

Energy efficiency is a relative concept, which refers to the amount of energy consumed to promote the sustainable development of economy, society and environment. At present, there are many researches on energy efficiency ${ }^{[1-2]}$. According to the number of indicators, energy efficiency can be divided into single factor energy efficiency and total factor energy efficiency ${ }^{[3]}$. Compared with the traditional single factor energy efficiency, total factor energy efficiency considers the influence of various factors, such as economic growth, industrial structure, technical level, environmental pollution. Therefore the energy efficiency calculation results more accurate and comprehensive.

In the aspect of energy efficiency measurement, there are two categories: parametric method and non parametric method. The parametric method is represented by SFA (Stochastic Frontier Analysis), which is first used by Schmidt P、Sickles R $\mathrm{C}^{[4]}$ and Gong B H、Sickles R $\mathrm{C}^{[5]}$. And the non parametric method is represented by DEA(Data Envelopment Analysis), which is more common in practical application than SFA. Wu et al. ${ }^{[6]}$ combined with principal component analysis to establish the DEA energy efficiency evaluation model which can deal with the non expected output, and make an empirical study on 30 administrative regions in china.

At present, the research object of energy efficiency is mainly concentrated in the level of national ${ }^{[7]}$, provincial ${ }^{[8]}$ and industry ${ }^{[9]}$. However, there is less research on energy efficiency of 
each segment. The research can be more appropriate from the micro level to provide quantitative data support for energy policy formulation. Under the background of industrial transfer in Beijing-Tianjin-Hebei, this paper uses the DEA-Malmquist and cluster analysis method to analyze the energy efficiency of various industries and differences. This can be targeted to formulate policies and measures to strengthen environmental constraints and improve energy efficiency to further promote the optimization of Beijing City and alleviate the pressure on resources and environment to provide a reference.

\section{Methodology}

\subsection{DEA model}

DEA is a mathematical programming model, which is operated by Charner, Cooper and Rhodes $^{[10]}$ in 1978. It's an non parametric statistics method, which is used to evaluate whether the same type of DMU(decision making unit) is effective. This method does not need to assume the production function, and can be directly input non homogeneous factors as the input indexes of total production frontier relative efficiency. The relative effective production frontier is determined by mathematical and statistical data, the production frontier of each decision unit is projected to the DEA, and through the comparison of decision making units deviate from the DEA frontier to evaluate their relative effectiveness. It has some advantages in dealing with multi-input and multi-output problems.

Consider there are $\mathrm{n}$ DMUs, and each DMU has $\mathrm{m}$ inputs and s outputs, $X_{i}=\left(x_{i 1}, x_{i 2} \ldots x_{i m}\right)^{T}$ and $Y_{i}=\left(y_{i 1}, y_{i 2} \ldots y_{i s}\right)^{T}$ are the $\mathrm{i}$-th DMU's input and output vector, respectively. The model to evaluate the efficiency value of the $\mathrm{i}$-th DMU is as follows:

$$
\text { s.t. }\left\{\begin{array}{l}
\min \theta \\
\sum_{i=0}^{n} X_{i} \lambda_{i}+S^{-}=\theta X_{0} \\
\sum_{i=0}^{n} Y_{i} \lambda_{i}-S^{+}=Y_{0} \\
\sum_{i=0}^{n} \lambda_{i}=1 \\
S^{-}, S^{+}, \lambda_{i} \geq 0
\end{array}\right.
$$

Where, $S^{-}$refers to the input's slack variable; $S^{+}$refers to the output's slack variable; ${ }^{i}$ indicates the weight of DMU; $\theta(0 \leq \theta \leq 1)$ is the efficiency score for the i-th DMU.

Malmquist index model

DEA model is used to evaluate the relative performance of each decision making unit in the whole evaluation system. For different evaluation systems in different periods, the efficiency values can not be compared directly. Based on the DEA model, Malmquist productivity index is proposed. based on the DEA model, using the ratio of the distance function to calculate the input-output efficiency. The model use the distance function to the ratio of input and output efficiency, and the decomposition of productivity change for change of technological progress and technical efficiency, technical efficiency and further subdivided into pure technical efficiency change and scale efficiency change.

Fare et al. ${ }^{[11]}$ defined a Malmquist productivity index based on constant returns to scale (CRS). The model is as follows: 


$$
m_{0}\left(y_{t+1}, x_{t+1}, y_{t}, x_{t}\right)=\left[\frac{d_{0}^{t}\left(x_{t+1}, y_{t+1}\right)}{d_{0}^{t}\left(x_{t}, y_{t}\right)} \times \frac{d_{0}^{t+1}\left(x_{t+1}, y_{t+1}\right)}{d_{0}^{t+1}\left(x_{t}, y_{t}\right)}\right]^{1 / 2}
$$

Where, $x_{t}, x_{t+1}$ are the input vectors in period $\mathrm{t}$ and $\mathrm{t}+1$, respectively; $y_{t}, y_{t+1}$ are the output vectors in period $\mathrm{t}$ and $\mathrm{t}+1$, respectively. $d_{0}^{t}$ and $d_{0}^{t+1}$ are distance functions between real output and optimal output based on CRS in period $t$ and period $t+1$, respectively.

Eq. 2 can be further expressed as the Malmquist productivity index containing the variable returns to scale(VRS) as follows:

$$
\begin{gathered}
m_{0}\left(y_{t+1}, x_{t+1}, y_{t}, x_{t}\right)= \\
\frac{d_{v}^{t+1}\left(x_{t+1}, y_{t+1}\right)}{d_{v}^{t}\left(x_{t}, y_{t}\right)} \times\left[\frac{d_{v}^{t}\left(x_{t}, y_{t}\right)}{d_{0}^{t}\left(x_{t}, y_{t}\right)} / \frac{d_{v}^{t+1}\left(x_{t+1}, y_{t+1}\right)}{d_{0}^{t+1}\left(x_{t+1}, y_{t+1}\right)}\right] \times\left[\frac{d_{0}^{t}\left(x_{t}, y_{t}\right)}{d_{0}^{t+1}\left(x_{t}, y_{t}\right)} \times \frac{d_{0}^{t}\left(x_{t+1}, y_{t+1}\right)}{d_{0}^{t+1}\left(x_{t+1}, y_{t+1}\right)}\right]^{1 / 2}
\end{gathered}
$$

Where, $d_{v}^{t}$ and $d_{v}^{t+1}$ are distance functions between real output and optimal output based on VRS in period $t$ and period $t+1$, respectively. The three items in Eq. 3 represent pure technical efficiency change, scale efficiency change and technological progress. Technological progress equals the product of pure technical efficiency change and technical progress. The change in technical efficiency measures the gap between each DMU from the period to the best frontier of $t+1$. Technological progress measures the movement of technological boundaries from $t$ to $t+1$. When the index is greater than 1 , equals to 1 and is less than 1 , it indicates technological progress, technology without change and technical setback, respectively.

\subsection{Index section}

In this paper, the energy efficiency of industry in Beijing is regarded as the research object. The data of 36 industries in Beijing city in 2005-2013 were analyzed. Table 1 lists all industry names and their serial numbers. Data source: Beijing Statistical Yearbook (2006-2014) and China

\begin{tabular}{|c|c|c|c|}
\hline Code & Industry name & Code & Industry name \\
\hline B1 & Coal mining and washing & B19 & Manufacturing of chemical fiber \\
\hline B2 & petroleum and gas extracting industry & $\mathrm{B} 20$ & Manufacturing of rubber \\
\hline B3 & Ferrous metal mining & B21 & Manufacturing of plastics \\
\hline B4 & Non-metal mining & $\mathrm{B} 22$ & Manufacturing of non-mental products \\
\hline B5 & Agricultural products processing & B23 & Smelting and rolling process of ferrous metal \\
\hline B6 & Food manufacturing & B24 & $\begin{array}{l}\text { Smelting and rolling process of non-ferrous } \\
\text { metal }\end{array}$ \\
\hline B7 & Beverage manufacturing & B25 & Manufacturing of metal products \\
\hline B8 & Textile industry & B26 & Manufacturing of ordinary equipment \\
\hline B9 & Textile clothes, shoes, hats manufacturing & B27 & Manufacturing of special equipment \\
\hline B10 & Leather, fur, feather manufacturing & B28 & Manufacturing of transportation equipment \\
\hline B11 & $\begin{array}{l}\text { Wood processing and bamboo, cane, palm and } \\
\text { straw manufacturing }\end{array}$ & B29 & Manufacturing of electric machines \\
\hline B12 & Furniture manufacturing & B30 & $\begin{array}{l}\text { Manufacturing of communication device, } \\
\text { computers and other electronic equipment }\end{array}$ \\
\hline B13 & Papermaking and paper products & B31 & $\begin{array}{l}\text { Manufacturing of instruments, cultural and } \\
\text { official mechanics }\end{array}$ \\
\hline B14 & Press and intermediary replication & B32 & Handicrafts and other Manufacturing \\
\hline B15 & $\begin{array}{l}\text { Cultural, educational and sports goods } \\
\text { manufacturing }\end{array}$ & B33 & $\begin{array}{l}\text { Resource waste and the processing of waste } \\
\text { material recycling }\end{array}$ \\
\hline B16 & $\begin{array}{l}\text { Oil processing, coking and nuclear fuels } \\
\text { processing }\end{array}$ & B34 & Production and supply of electricity, power \\
\hline B17 & $\begin{array}{l}\text { Manufacturing of chemical materials and } \\
\text { products }\end{array}$ & B35 & Gas production and supply \\
\hline $\mathrm{B} 18$ & Manufacturing of medicines & B36 & Water production and supply \\
\hline
\end{tabular}
Statistical Yearbook (2006-2014).

Table 1 Codes and names of 36 sub-industries in Beijing.

Based on DEA-Malmquist model, this paper selects capital stock, labor and energy 
consumption as input indicators, and selects industrial added value as desirable output and $\mathrm{CO}_{2}$ emission as undesirable output to measure the total energy efficiency and the decomposed index of 36 industries in Beijing.

(1) Capital stock. It is represented by the average annual net value of fixed assets and reduces to 2005 according to the industry price of products. (Unit: one billion)

(2) Labor. Because the statistical index does not reflect the labor time and efficiency, considering the availability of data and comparability, the average number of employees in the industry indicate the labor input. (Unit: thousand)

(3) Energy consumption. The annual total energy consumption of each industry is regarded as the indicators, equivalent to standard coal. (Unit: one million tons)

(4) Industrial added value. The annual industrial added value of each industry reduces to 2005 according to the various sectors of the industrial producer price index. (Unit: one billion)

(5) The $\mathrm{CO}_{2}$ emission. According to the 'Chinese energy statistics yearbook 2012'in the conversion coefficient, the terminal energy consumption converted into standard coal quantity. And calculate the annual industrial carbon dioxide emissions according to the carbon emissions coefficients in '2006 IPCC national greenhouse gas inventory guidelines'.

\section{Empirical Analysis}

\subsection{Analysis of total factor energy efficiency in industry}

In order to compare the differences of energy efficiency among different industries, from the perspective of industry segments, the total factor energy efficiency values of 36 industrial sectors in Beijing were calculated (Table 2). Using of SPSS23 in the system clustering model and using group connection method and the squared Euclidean distance to measure the similarity between the lines, high, medium and low three levels of classification of the various sectors of the industry, the classification results are shown in table 3.

Table 2 The total factor energy efficiency values of 36 sub-industries in Beijing(2005-2013)

\begin{tabular}{ccccccccccc} 
Code & 2005 & 2006 & 2007 & 2008 & 2009 & 2010 & 2011 & 2012 & 2013 & mean \\
\hline B1 & 1 & 1 & 1 & 1 & 1 & 1 & 1 & 1 & 1 & 1 \\
B2 & 1 & 1 & 1 & 0.569 & 0.742 & 0.541 & 0.537 & 1 & 0.985 & 0.819 \\
B3 & 1 & 0.755 & 1 & 1 & 0.965 & 0.331 & 0.471 & 0.146 & 0.505 & 0.686 \\
B4 & 0.244 & 0.317 & 0.309 & 0.164 & 0.196 & 0.073 & 0.321 & 0.168 & 0.224 & 0.224 \\
B5 & 0.441 & 0.253 & 0.236 & 0.159 & 0.202 & 0.201 & 0.2 & 0.227 & 0.252 & 0.241 \\
B6 & 0.634 & 0.494 & 0.41 & 0.303 & 0.371 & 0.25 & 0.229 & 0.212 & 0.375 & 0.364 \\
B7 & 0.597 & 0.593 & 0.536 & 0.431 & 0.638 & 0.442 & 0.422 & 0.47 & 0.594 & 0.525 \\
B8 & 0.367 & 0.316 & 0.29 & 0.229 & 0.34 & 0.165 & 0.283 & 0.191 & 0.275 & 0.273 \\
B9 & 0.408 & 0.367 & 0.26 & 0.424 & 0.461 & 0.282 & 0.275 & 0.396 & 0.34 & 0.357 \\
B10 & 0.255 & 0.241 & 0.282 & 0.276 & 0.436 & 0.212 & 0.232 & 0.277 & 0.245 & 0.273 \\
B11 & 0.157 & 0.214 & 0.296 & 0.146 & 0.157 & 0.162 & 0.128 & 0.154 & 0.199 & 0.179 \\
B12 & 0.285 & 0.31 & 0.24 & 0.294 & 0.311 & 0.207 & 0.238 & 0.347 & 0.286 & 0.28 \\
B13 & 0.549 & 0.499 & 0.519 & 0.459 & 0.662 & 0.467 & 0.778 & 0.722 & 0.642 & 0.589 \\
B14 & 0.317 & 0.324 & 0.317 & 0.381 & 0.38 & 0.319 & 0.397 & 0.448 & 0.389 & 0.364 \\
B15 & 0.345 & 0.328 & 0.182 & 0.18 & 0.252 & 0.17 & 0.194 & 0.443 & 0.267 & 0.262 \\
B16 & 0.829 & 0.464 & 0.604 & 1 & 1 & 1 & 0.966 & 0.77 & 1 & 0.848 \\
\hline & & & & & & & & & &
\end{tabular}


Table 2, cont.

\begin{tabular}{ccccccccccc}
\hline B17 & 0.523 & 0.446 & 0.548 & 0.292 & 0.449 & 0.471 & 0.435 & 0.302 & 0.526 & 0.444 \\
B18 & 0.652 & 0.654 & 0.792 & 1 & 1 & 0.793 & 0.876 & 1 & 1 & 0.863 \\
B19 & 0.652 & 0.383 & 0.37 & 0.359 & 0.421 & 0.271 & 0.414 & 0.466 & 0.466 & 0.422 \\
B20 & 0.257 & 0.216 & 0.169 & 0.184 & 0.27 & 0.161 & 0.175 & 0.443 & 0.266 & 0.238 \\
B21 & 0.316 & 0.279 & 0.291 & 0.254 & 0.366 & 0.248 & 0.345 & 0.347 & 0.336 & 0.309 \\
B22 & 0.308 & 0.292 & 0.281 & 0.166 & 0.393 & 0.316 & 0.333 & 0.325 & 0.369 & 0.309 \\
B23 & 1 & 1 & 1 & 0.446 & 0.371 & 0.317 & 0.019 & 0.087 & 0.84 & 0.564 \\
B24 & 0.464 & 0.376 & 0.242 & 0.277 & 0.353 & 0.285 & 0.636 & 0.552 & 0.437 & 0.402 \\
B25 & 0.35 & 0.317 & 0.401 & 0.375 & 0.401 & 0.272 & 0.342 & 0.394 & 0.39 & 0.36 \\
B26 & 0.512 & 0.534 & 0.54 & 0.564 & 0.554 & 0.552 & 0.67 & 0.62 & 0.635 & 0.576 \\
B27 & 0.559 & 0.604 & 0.497 & 0.593 & 0.557 & 0.484 & 0.554 & 0.569 & 0.611 & 0.559 \\
B28 & 0.661 & 0.603 & 0.686 & 0.747 & 0.999 & 1 & 1 & 1 & 1 & 0.855 \\
B29 & 0.887 & 0.574 & 0.661 & 0.76 & 0.982 & 0.6 & 0.624 & 0.605 & 0.789 & 0.72 \\
B30 & 1 & 1 & 1 & 0.977 & 0.78 & 0.678 & 0.53 & 0.487 & 0.955 & 0.823 \\
B31 & 1 & 1 & 1 & 1 & 1 & 1 & 1 & 0.961 & 1 & 0.996 \\
B32 & 0.384 & 0.485 & 0.754 & 0.665 & 0.631 & 0.238 & 0.394 & 0.286 & 0.519 & 0.484 \\
B33 & 0.5 & 0.627 & 0.622 & 0.309 & 0.428 & 0.248 & 0.212 & 0.344 & 0.452 & 0.416 \\
B34 & 0.96 & 1 & 1 & 1 & 1 & 1 & 1 & 0.272 & 1 & 0.915 \\
B35 & 0.546 & 0.641 & 0.805 & 1 & 1 & 0.642 & 0.446 & 0.242 & 0.847 & 0.685 \\
B36 & 0.314 & 0.308 & 0.204 & 0.338 & 0.37 & 0.148 & 0.225 & 0.066 & 0.287 & 0.251 \\
\hline & & & & & & & & & & \\
\hline
\end{tabular}

Table 3 The cluster analysis about energy efficiency of 36 sub-industries of Beijing

\begin{tabular}{|c|c|c|c|c|c|}
\hline & & & GDP ratio & $\begin{array}{l}\text { energy } \\
\text { consumptio } \\
\text { n ratio }\end{array}$ & $\begin{array}{l}\text { energy intensity } \\
\text { (tons of coal/ } \\
\text { ton })\end{array}$ \\
\hline \multirow{2}{*}{$\begin{array}{l}\text { high } \\
\text { efficiency }\end{array}$} & heavy industry & $\begin{array}{l}\mathrm{B} 1 、 \mathrm{~B} 2 、 \mathrm{~B} 16 、 \mathrm{~B} 18 、 \mathrm{~B} 28 、 \\
\mathrm{~B} 31 、 \mathrm{~B} 34 、 \mathrm{~B} 23 、 \mathrm{~B} 29 、 \mathrm{~B} 30 、 \\
\mathrm{~B} 35\end{array}$ & $71 \%$ & $58 \%$ & 0.58 \\
\hline & light industry & & $0 \%$ & $0 \%$ & 0 \\
\hline \multirow{2}{*}{$\begin{array}{l}\text { medium } \\
\text { efficiency }\end{array}$} & heavy industry & $\begin{array}{l}\text { B26、B27、B17、B3、B19、 } \\
\text { B33、B24 }\end{array}$ & $13 \%$ & $17 \%$ & 1.04 \\
\hline & light industry & B13、B7、B32 & $3 \%$ & $3 \%$ & 0.74 \\
\hline \multirow[b]{2}{*}{$\begin{array}{l}\text { low } \\
\text { efficiency }\end{array}$} & heavy industry & $\mathrm{B} 25 、 \mathrm{~B} 22 、 \mathrm{~B} 4 、 \mathrm{~B} 20$ & $5 \%$ & $13 \%$ & 1.95 \\
\hline & light industry & $\begin{array}{l}\text { В14、B6、B9、B21、B36、 } \\
\text { B12、B8、B15、B5、B10、 } \\
\text { B11 }\end{array}$ & $8 \%$ & $9 \%$ & 0.81 \\
\hline
\end{tabular}

The energy efficiency among industries in Beijing are significantly different, and some industries still have great potential for energy saving. The average energy efficiency of high energy efficiency industry, middle energy efficiency industry and low energy efficiency industry was $0.94,0.54$ and 0.302 respectively. The traditional "three high" industries such as coal mining and washing industry, oil exploitation and processing, metal smelting exist in the industry of high energy efficiency, but the most companies of which have turned out or shut down. At present, the total number of enterprises in this industry is only 13 , and the gross value 
of high energy efficiency industry is no more than $6 \%$ of industry. Other industries with high energy efficiency are mostly manufacturing enterprises, which size is large-scale or medium-scale. The main reason for this situation is that large or medium-scale companies have good resources such as labor, equipment and money to promote the reform of technology and management system persistently compared with small-scale companies, and another reason is that large and medium-sized manufacturing enterprises assume more social responsibility than the small-scale companies, so they play a important role in promoting the energy efficiency with the energy saving and emission reduction policy and the social pressure.

The energy efficiency in $80 \%$ of the heavy industry is medium and high. Only four industries including manufacturing of metal products, manufacturing of non-mental products, manufacturing of rubber and non-metal mining is low. From the early state of ' 11 th Five Year Plan', the chemical, cement, printing and dyeing, building materials and other heavy industrial production enterprises has continuously been moved out from Beijing. Meanwhile, driven by industrial restructuring and industrial transfer, the Beijing industrial investment gradually transfers to the automotive, electronics, medicine and high-end equipment. It is the champion in the communications equipment, computers and other electronic equipment manufacturing, and has formed the trend of the development of industrial clusters. In 2015, the Ministry of industry and Commerce in Beijing-Tianjin- Hebei Province, the directory has eight categories of key industries, including information technology and equipment manufacturing industry in the energy efficiency of the top two categories of industrial.

The energy efficiency of light industry is low, except for papermaking and paper products, beverage manufacturing, and handicrafts and other manufacturing. At present, the market potential of clothing, shoes and hats manufacturing, leather, fur, feathers (down) and its products industry, furniture manufacturing and other market potential in Beijing are small, belonging to the labor-intensive industries and polluting industries, and is the key industries in the future of industrial transfer. In 2014, the first batch relocation of enterprises involves a total of 2017 in Beijing, including building materials, chemicals, furniture, clothing, textile industry and other enterprises, which is consistent with the low efficiency of the industry cluster analysis.

\subsection{Total factor productivity index and its decomposition analysis}

The total factor productivity (TFP) can measure the productivity change, which is decomposed into technological progress (TP), technical efficiency(TE). The technical efficiency can further be decomposed into pure technical efficiency(PTE) and scale efficiency(SE). After mining 1, the index is the annual growth rate. We measure the malmquist index and its decomposed results with DEA-Malmquist model in Beijing industry from 2005 to 2013. The results are shown in table 4.

Table 4 The Malmquist index and its decomposed index of the industry sector in Beijing from 2005-2013

\begin{tabular}{ccccccccccc}
\hline \multirow{2}{*}{ industry } & \multirow{2}{*}{ index } & $2005-$ & $2006-$ & $2007-$ & $2008-$ & $2009-$ & $2010-$ & $2011-$ & $2012-$ & \multirow{2}{*}{ mean } \\
& & 2006 & 2007 & 2008 & 2009 & 2010 & 2011 & 2012 & 2013 & \\
\hline \multirow{6}{*}{ total } & TE & 0.931 & 0.99 & 1.018 & 1.179 & 0.706 & 1.077 & 0.984 & 1.017 & 0.969 \\
& TP & 1.057 & 1.141 & 1.044 & 0.912 & 1.271 & 0.942 & 1.175 & 1.065 & 1.083 \\
& PTE & 0.898 & 1.007 & 1.033 & 1.086 & 0.809 & 0.995 & 0.981 & 0.992 & 0.979 \\
& SE & 1.037 & 0.983 & 0.985 & 1.085 & 0.873 & 1.083 & 1.004 & 1.026 & 0.99 \\
& TFP & 0.984 & 1.13 & 1.062 & 1.076 & 0.897 & 1.015 & 1.156 & 1.083 & 1.05 \\
\multirow{5}{*}{ inght } & & & & & & & & & & \\
& TE & 1.074 & 0.775 & 1.058 & 1.145 & 1.107 & 0.85 & 1.006 & 1.035 & 0.979 \\
& TP & 0.923 & 1.521 & 0.995 & 0.984 & 0.857 & 1.201 & 1.02 & 1.016 & 1.054 \\
& PTE & 1.033 & 0.878 & 1.031 & 1.077 & 1.059 & 0.921 & 1.021 & 1.043 & 0.986 \\
& SE & 1.04 & 0.883 & 1.026 & 1.062 & 1.046 & 0.923 & 0.985 & 0.992 & 0.993 \\
\hline
\end{tabular}


Table 4, cont.

\begin{tabular}{ccccccccccc}
\hline \multirow{7}{*}{ TFP } & 0.991 & 1.179 & 1.052 & 1.127 & 0.949 & 1.02 & 1.026 & 1.052 & 1.032 \\
& & & & & & & & & & \\
industry & TE & 0.898 & 1.023 & 0.899 & 1.15 & 0.769 & 1.097 & 0.824 & 0.926 & 0.943 \\
& TP & 1.031 & 1.072 & 1.073 & 0.906 & 1.281 & 0.866 & 1.44 & 1.247 & 1.09 \\
& SE & 0.891 & 1.056 & 0.978 & 1.072 & 0.914 & 0.947 & 0.91 & 0.942 & 0.965 \\
& TFP & 0.926 & 1.097 & 0.965 & 1.042 & 0.986 & 0.95 & 1.187 & 1.155 & 1.068 \\
\hline
\end{tabular}

From the table 4 , the industrial energy efficiency of Beijing showed a growth trend, with an average annual growth rate of 5\% for the whole industry, $3.2 \%$ and $6.8 \%$ for the light industry and heavy industry, respectively. From the development process, before 2009, industrial energy efficiency is on the rise, mainly due to the Olympic Games in 2008, which is an opportunity to achieve the development of energy by leaps and bounds. And industrial restructuring, energy-saving emission reduction achieved remarkable results. In 2009-2010, under the effect of international financial crisis, the government invested a lot of money to support the development of the industry, but the high input of capital didn't bring industrial added value, even showing negative growth. After 2010, the impact of the financial crisis gradually subsided, and the economic situation improved. Meanwhile, in the early stage of "12th Five Year Plan", the review mechanism of new industrial project energy equipment is strict. The large-scale, labor-intensive heavy industry enterprises are ongoing technological transformation and industrial upgrading while relocation, which can further promote the optimization of industrial structure and improve the industrial energy efficiency.

After the decomposition of total factor productivity index, the annual growth rate of technological progress is $8.3 \%$, which is the main factors of energy efficiency improvement in Beijing's industry. However, the annual growth rate of technical efficiency index is $-3.1 \%$, which indicates the input of industrial sector in Beijing has not been fully utilized and there is a loss of resource allocation efficiency. The scale efficiency and technical efficiency have positive effect on energy efficiency, whose annual growth rates are $-1 \%$ and $-2.1 \%$, respectively. The pure technical efficiency is mainly affected by enterprise management and institutional arrangements, which should be the focus to improve the energy efficiency.

The technological progress of heavy industry and light industry are $9 \%$ and $5.4 \%$, respectively, and the promotion effect on heavy effect is greater than light industry. Some labor-intensive industries in light industry are hard to carry out technological transformation and industrial upgrading. And most of them enter into the enterprise just fancy its cheap labor. However, the technological transformation measures have significant effects on capital-intensive large and medium sized heavy industry, and the technical level of capital-intensive industries are high. Most light industrial enterprises are highly open and highly competitive, while the heavy industry enterprises open low, high degree of monopoly. So the pure technical efficiency of the impact of light industry is less than heavy industry.

\section{Conclusions}

Under the background of industrial transfer in Beijing-Tianjin-Hebei, this paper measures the total factor energy efficiency in 36 industries in Beijing from 2005 to 2015 and is in cluster analysis. Then it measures the total factor productivity index and its decomposed index of the whole industry, light industry and heavy industry in 2005-2013. The conclusions are as follows:

(1) There are significant differences in energy efficiency in different industries. $80 \%$ of heavy industries are belong to the medium or high energy efficiency industry, while the light industry is located in medium and low energy efficiency. Heavy industry is superior to light industry in terms of technology import and capital investment, and its energy efficiency is obviously higher than that of light industry. 
(2) Through the Malmquist total factor productivity index, the energy efficiency of Beijing's industry increased in 2005-2013, and the average annual growth rate is 5\%. The main driving factor is technological progress, whose average growth rate is $8.3 \%$. And the main obstacle factor is pure technical efficiency, whose average annual growth rate is $-2.1 \%$.

(3) The influence of each factor on light industry and heavy industry is the same, but the influence is different. Technological progress on the promotion of heavy industry is greater than the light industry. The main reason is that the heavy industry mostly is capital-intensive industries and it's easy to carry out technological transformation and industrial upgrading. However, the impact of technological efficiency on light industry is less than that of heavy industry. Compared with heavy industry, most light industrial enterprises are highly open and competitive.

\section{Acknowledgments}

This paper was supported by the Social Science Foundation of Beijing (Project ID 15JGB050).

\section{References}

[1] G. Hondroyiannis, S. Lolos, and E. Papapetrou. Energy consumption and economic growth: assessing the evidence from Greece. Energy Economics. 2002, 24(4):319-336.

[2] K. Tanaka, "Review of policies and measures for energy efficiency in industry sector," Energy Policy, 2011, 39(10): 6532-6550.

[3] Wang Z H, Zeng H L, Wei Y M, et al. Regional total factor energy efficiency: anempirical analysis of industrial sector in China[J]. Applied Energy, 2012, 97: 115-123.

[4] Schmidt P, Sickles R C. Production frontiers and panel data [J]. Journal of Business \& Economic Statistics, 1984, 2(4): 367-374.

[5] Gong B H, Sickles R C. Finite sample evidence on the performance of stochastic frontiers and data envelopment analysis using panel data [J]. Journal of Economics, 1992, 51(1): 259-284.

[6] Wu Q, Wu C Y. Research on Evaluation Model of Energy Efficiency Based on DEA. Journal of management science. 2009, 2(1):103-112.

[7] Satoshi Honma, Jin-Li Hu. Industry-level total-factor energy efficiency in developed countries: A Japan-centered analysis [J].Applied Energy, 2014;119:67-78.

[8] Chen Y, Cook W D, Du J, et al. Bounded and discrete data and Likert scales in data envelopment analysis: application to regional energy efficiency in China[J]. Annals of Operations Research, 2015: 1-20.

[9] Eva Henriksson, Patrik Söderholm, Linda Wårell. Industrial electricity demand and energy efficiency policy: the case of the Swedish mining industry [J]. Energy Efficiency, 2014;7:477-491.

[10] Charnes A, Cooper W W, Rhodes E. Measuring the efficiency of DMU [J]. European Journal of Operational Research, 1978,2(6): 429-444.

[11] Fare, R., Grosskopf, S., Russell, R.R.. Index Numbers:Essays in Honor of Sten Malmquist[M]. Boston:Kluwer Academic Publishers, 1998. 